\title{
Analysis of the efficacy and safety of bortezomib for treating newly diagnosed multiple myeloma through different administration methods
}

This article was published in the following Dove Press journal: Cancer Management and Research

\author{
Hong-Mei Zhang \\ Xi-Yang Liu \\ Yu-Zhang Liu \\ Li-Na Liu \\ Quan-De Lin \\ Yong-Ping Song \\ Bai-Jun Fang
}

Department of Hematology, Henan Institute of Haematology, Henan Cancer Hospital, the Affliated Cancer Hospital of Zhengzhou University, Zhengzhou University, Zhengzhou 450008, People's Republic of China
Correspondence: Bai-Jun Fang

Department of Hematology, Henan Institute of Haematology, Henan Cancer Hospital, The Affliated Cancer Hospital of Zhengzhou University, Zhengzhou University, No. 127 Dongming Road, Zhengzhou 450008, People's Republic of China

Tel +8637165587318

Fax +8637165588134

Email bjfdr_sea@l63.com
Background: This study aims to compare the efficacy and adverse reactions of bortezomib for treating newly diagnosed multiple myeloma (MM) through two different administration methods: intravenous (IV) injection and subcutaneous (SC) injection.

Methods: A retrospective analysis was performed in 205 patients with newly diagnosed MM, who were treated by the Department of Hematopathology, Henan Cancer Hospital, from June 2009 to December 2017. These patients were divided into two groups according to the treatment methods: IV injection group, IV injection of bortezomib; SC injection group, $\mathrm{SC}$ injection of bortezomib.

Results: After the first course of treatment, the effect of very good partial remission (VGPR) or above ( $\geq$ VGPR) in the IV injection group (IV group) and SC injection group (SC group) was $31.0 \%$ and $14.3 \%$, respectively $(P=0.004)$, while the overall response rate (ORR) was $72.0 \%$ and $49.5 \%$, respectively $(P=0.001)$. From the 2 nd course to the 6 th course of treatment, the ORR was not statistically different between these two groups. No significant difference was found in median progression-free survival (37 vs 45 months) and overall survival (63 vs 59 months). A lower frequency of adverse events, especially Grade 3 peripheral neuropathy, was observed in SC group compared with the IV group.

Conclusion: Compared with IV administration, SC bortezomib can provide a better balance between efficacy and toxicity.

Keywords: multiple myeloma, bortezomib, intravenous injection, subcutaneous injection

\section{Introduction}

Multiple myeloma (MM), the malignant tumor of the plasma cells, comprises of approximately $1.8 \%$ of cancers and $17 \%$ of hematological malignancies. At present, this disease has remained incurable with a high recurrence rate. ${ }^{1}$ The use of proteasome inhibitor bortezomib and glucocorticoids is the standard scheme for newly diagnosed and recurrent/refractory $\mathrm{MM}$, and it can improve the effect of MM significantly. ${ }^{2-4}$ The traditional administration method of bortezomib adopts intravenous (IV) injection. However, during the treatment process, some patients would suffer from adverse reactions, such as hematological toxicity, infection, peripheral neuropathy $(\mathrm{PN})$, herpes zoster and digestive tract symptoms, and further treatments would be mostly affected by PN. In order to reduce the occurrence of PN, other countries attempted a new administration method, subcutaneous (SC) injection. ${ }^{5,6} \mathrm{SC}$ administration of bortezomib was reported could reduce toxicity without loss of efficacy compared with the conventional intravenous (IV) bolus 
injections. ${ }^{6}$ But there are very limited data available about the safety and efficacy profile of SC bortezomib in Chinese and Asian patients with newly diagnosed MM.

The present study performs a retrospective comparison of the efficacy and safety of bortezomib for treating newly diagnosed $\mathrm{MM}$ in China through SC injection and IV injection.

\section{Materials and methods}

\section{Case data}

The clinical data of 205 patients with MM, who were diagnosed by the Department of Hematopathology, Henan Cancer Hospital, and treated with bortezomib from June 2009 to December 2017, were collected. The diagnosis, periodization and efficacy evaluation of MM were based on the MM NCCN diagnosis and treatment guidelines. ${ }^{7}$ All patients took the initial treatment, but the hematopoietic stem cell transplantation was not carried out due to the economy, age and physical condition. At least six courses of treatment were completed. This study was conducted in accordance with the declaration of Helsinki and approved by the Ethics Committee of our hospital. The written informed consent was obtained from all participants.

\section{Treatment scheme}

There are three schemes: VD (bortezomib and dexamethasone), VCD (bortezomib, cyclophosphamide and dexamethasone) and VAD (bortezomib, doxorubicin and dexamethasone). A total of 100 patients received bortezomib through IV injection (IV group): bortezomib, $1.3 \mathrm{mg} / \mathrm{m}^{2}$, which was performed at the 1st, 4th, 8th and 11th day; 21 days were considered one course of treatment. A total of 105 patients received bortezomib through SC injection (SC group): bortezomib, $1.3 \mathrm{mg} / \mathrm{m}^{2}$, which was performed at the 1st, 4th, 8th and 11th day; 21 days were considered one course of treatment. If the patient suffered from level 1-3 PN, paralytic bowel infarction, severe infection and other severe adverse reactions after the use of bortezomib, the dose of bortezomib was allowed to adjust to $1.0 \mathrm{mg} / \mathrm{m}^{2}$, or the weekly dosage regimen was adopted. Cyclophosphamide through IV injection was given at a dose of $900 \mathrm{mg} / \mathrm{m}^{2}$ on day 1 at each cycle. Doxorubicin through IV injection was given at a dose of $9 \mathrm{mg} / \mathrm{m}^{2}$ on days 1 through 4 at each cycle.

\section{Follow-up}

Clinical and telephone follow-ups were mainly performed, and the follow-up deadline expired on November 30 , 2018.

\section{Evaluation of efficacy and adverse reactions}

The evaluation of the efficacy was performed after every course of treatment, including complete remission (CR), very good partial remission (VGPR), partial remission (PR), minor remission (MR), stable disease (SD) and progression of disease (PD), in accordance with the International Myeloma Working Group's uniform response criteria for MM. ${ }^{5,7}$ Overall survival (OS) time: from the patient's treatment to death or loss to follow-up. Progression-free survival (PFS) time: from the patient's treatment to the progression or death caused by any reason. The evaluation of the adverse reactions was performed from the aspect of hematological toxicity, digestive tract symptoms, PN, pulmonary infection/upper respiratory infection, herpes zoster and hepatic injury.

\section{Statistical process}

The SPSS21.0 software was used for analysis, $X^{2}$-test was used for comparing among categorical data groups, the Kaplan-Meier method was used to describe the PFS and OS curve and log-rank test was used for comparisons among groups. $P<0.05$ was considered statistically significant.

\section{Results}

\section{Basic clinical features of patients}

Among the 205 patients, 122 patients were male and 83 patients were female, and their median age was 61 years (range: 27-82 years). Immunophenotyping: 22 patients were tested to be IgA $\mathrm{k}$ type, 28 patients were IgA $\lambda$ type, 48 patients were $\operatorname{IgG~} \mathrm{k}$ type, 57 patients were $\operatorname{IgG} \lambda$ type, 1 patient was IgD $\mathrm{k}$ type, 15 patients were $\mathrm{k}$ type, 33 patients were $\lambda$ type and 1 patient had no secreting type. Furthermore, a total of 46 patients suffered from renal insufficiency. The differences in gender, age, typing, periodization and cytogeneticity among the patients of these two groups were not statistically significant (Table 1), but were comparable.

\section{Efficacy and outcome}

In the IV injection group, the overall response rate (ORR = CR + VGPR + PR) was 72.0\%, 75.0\% and $77.0 \%$, respectively, after the 1st, 2 nd and 3rd courses of treatment, $81.0 \%$ after the 4 th course of treatment, $82.0 \%$ after the 5 th course of treatment and $83.0 \%$ after the 6th course of treatment. In the SC injection group, the ORR was $49.5 \%, 72.4 \%$ and 
Table I Baseline characteristics of patients in the IV group and the SC group

\begin{tabular}{|c|c|c|c|c|}
\hline Characteristics & $\begin{array}{l}\text { IV Group } \\
(\mathrm{N}=100)\end{array}$ & $\begin{array}{l}\text { SC Group } \\
(\mathrm{N}=105)\end{array}$ & $\mathrm{CHI}^{2}$ & $P$-value \\
\hline $\begin{array}{l}\text { Gender (male/ } \\
\text { female) }\end{array}$ & $58 / 42$ & $64 / 41$ & 0.185 & 0.667 \\
\hline Age, y & $62(32-82)$ & $59(27-8 I)$ & 2.694 & 0.101 \\
\hline $\begin{array}{l}\text { M-spike isotype } \\
\qquad \begin{array}{l}\lg A \\
\lg G \\
\lg D \\
K \\
\lambda\end{array}\end{array}$ & $\begin{array}{l}27(27.0) \\
52(52.0) \\
- \\
6(6.0) \\
14(14.0)\end{array}$ & $\begin{array}{l}23(21.9) \\
53(50.5) \\
1(0.9) \\
9(8.6) \\
19(18.1)\end{array}$ & 3.567 & 0.613 \\
\hline Non-secretory & I (I.0) & - & & \\
\hline $\begin{array}{c}\text { DS } \\
\text { I } \\
\text { II } \\
\text { III }\end{array}$ & $\begin{array}{l}5(5.0) \\
21(21.0) \\
74(74.0)\end{array}$ & $\begin{array}{l}9(8.6) \\
23(21.9) \\
73(69.5)\end{array}$ & 1.119 & 0.571 \\
\hline $\begin{array}{l}\text { ISS } \\
\text { I } \\
\text { II } \\
\text { III }\end{array}$ & $\begin{array}{l}25(25.0) \\
38(38.0) \\
37(37.0)\end{array}$ & $\begin{array}{l}22(21.0) \\
43(40.9) \\
40(38.1)\end{array}$ & 0.495 & $0.78 \mathrm{I}$ \\
\hline $\begin{array}{l}\text { Regimen } \\
\text { VD } \\
\text { VCD } \\
\text { VAD }\end{array}$ & $\begin{array}{l}50(50.0) \\
33(33.0) \\
17(17.0)\end{array}$ & $\begin{array}{l}56(53.3) \\
30(28.6) \\
19(18.1)\end{array}$ & 0.472 & 0.790 \\
\hline $\begin{array}{l}\text { Reduction or } \\
\text { delay of treatment }\end{array}$ & $38(38.0)$ & 31 (29.5) & 1.648 & 0.199 \\
\hline
\end{tabular}

Notes: VD (bortezomib and dexamethasone), VCD (bortezomib, cyclophosphamide and dexamethasone), and VAD (bortezomib, doxorubicin and dexamethasone).

Abbreviations: IV, intravenous; SC, subcutaneous; DS, Durie-Salmon System; ISS, International Staging System.

$78.1 \%$, respectively, after the 1 st, 2 nd and 3 rd courses of treatment, $80.0 \%$ after the 4 th course of treatment, $81.0 \%$ after the 5th course of treatment and $81.9 \%$ after the 6 th course of treatment. After the 1st course of treatment, the remission rate of VGPR or above $(\geq \mathrm{VGPR})$ in the IV injection group and $\mathrm{SC}$ injection group was $31.0 \%$ and $14.3 \%$, respectively, and the difference was statistically significant $(P=0.004<0.05)$. The ORR was $72.0 \%$ and $49.5 \%$, respectively, and the difference was statistically significant $(P=0.001<0.05)$. From the 2 nd to 6 th courses of treatment, the ORR was not statistically different between these two groups ( $P>0.05$, Table 2$)$.

The median follow-up time for the IV injection group and SC injection group was 42 months (range: 2-105 months) and 24 months (range: 1-96 months), respectively.
Table 2 The response after every cycle

\begin{tabular}{|c|c|c|c|c|}
\hline & $\begin{array}{l}\text { IV Group, } \\
\text { N (\%) }\end{array}$ & $\begin{array}{l}\text { SC Group, } \\
\text { N (\%) }\end{array}$ & $\mathrm{CHI}^{2}$ & $P$-value \\
\hline \multicolumn{5}{|l|}{ Cycle I } \\
\hline $\mathrm{CR}$ & $15(15.0)$ & $13(12.4)$ & 0.298 & 0.585 \\
\hline$\geq \mathrm{VGCR}$ & 31 (3I.0) & $15(14.3)$ & 8.222 & 0.004 \\
\hline$\geq P R$ & $72(72.0)$ & $52(49.5)$ & 10.826 & 0.001 \\
\hline \multicolumn{5}{|l|}{ Cycle 2} \\
\hline $\mathrm{CR}$ & $16(16.0)$ & 17 (16.2) & 0.001 & 0.970 \\
\hline$\geq V G C R$ & $35(35.0)$ & $28(26.7)$ & I.67| & 0.196 \\
\hline$\geq P R$ & $75(75.0)$ & $76(72.4)$ & 0.181 & 0.670 \\
\hline \multicolumn{5}{|l|}{ Cycle 3} \\
\hline CR & $21(21.0)$ & $29(27.6)$ & 1.217 & 0.270 \\
\hline$\geq \mathrm{VGCR}$ & $37(37.0)$ & 44 (4I.9) & 0.516 & 0.473 \\
\hline$\geq P R$ & $77(77.0)$ & $82(78.1)$ & 0.035 & 0.851 \\
\hline \multicolumn{5}{|l|}{ Cycle 4} \\
\hline CR & $29(29.0)$ & $33(31.4)$ & 0.143 & 0.705 \\
\hline$\geq \mathrm{VGCR}$ & $49(49.0)$ & $52(49.5)$ & 0.006 & 0.940 \\
\hline$\geq P R$ & 81 (8I.0) & $84(80.0)$ & 0.033 & 0.857 \\
\hline \multicolumn{5}{|l|}{ Cycle 5} \\
\hline $\mathrm{CR}$ & $34(34.0)$ & $4 \mid(39.0)$ & 0.562 & 0.453 \\
\hline$\geq \mathrm{VGCR}$ & $52(52.0)$ & $53(50.5)$ & 0.048 & 0.827 \\
\hline$\geq P R$ & $82(82.0)$ & $85(81.0)$ & 0.037 & 0.847 \\
\hline \multicolumn{5}{|l|}{ Cycle 6} \\
\hline $\mathrm{CR}$ & $40(40.0)$ & $50(47.6)$ & 1.207 & 0.272 \\
\hline$\geq \mathrm{VGCR}$ & $54(54.0)$ & $59(56.2)$ & 0.099 & 0.753 \\
\hline$\geq \mathrm{PR}$ & $83(83.0)$ & $86(81.9)$ & 0.042 & 0.837 \\
\hline
\end{tabular}

Abbreviations: IV, intravenous; SC, subcutaneous; CR, complete response; VGPR, very good partial response; PR, partial response.

The median PFS was higher in the IV injection group than in the SC injection group (37 months vs 45 months), but the difference was not statistically significant $\left(X^{2}=0.082\right.$, $P=0.774)$. The median OS was higher in the IV injection group than in the SC injection group (63 months vs 59 months), but the difference was not statistically significant $\left(X^{2}=0.185, P=0.667\right)$ (Figures 1 and 2).

\section{Adverse reactions (Table 3) Hematological toxicity}

Compared with the SC injection group, the incidence of leukopenia was higher in the IV injection group, while the incidence of hemoglobin decrease and thrombocytopenia was lower in the IV injection group, but both were not statistically significant. After the chemotherapy, blood routine examination was carried out for a number of times, and the hemogram rose, when compared with the period of treatment after the symptomatic and supportive treatment. 


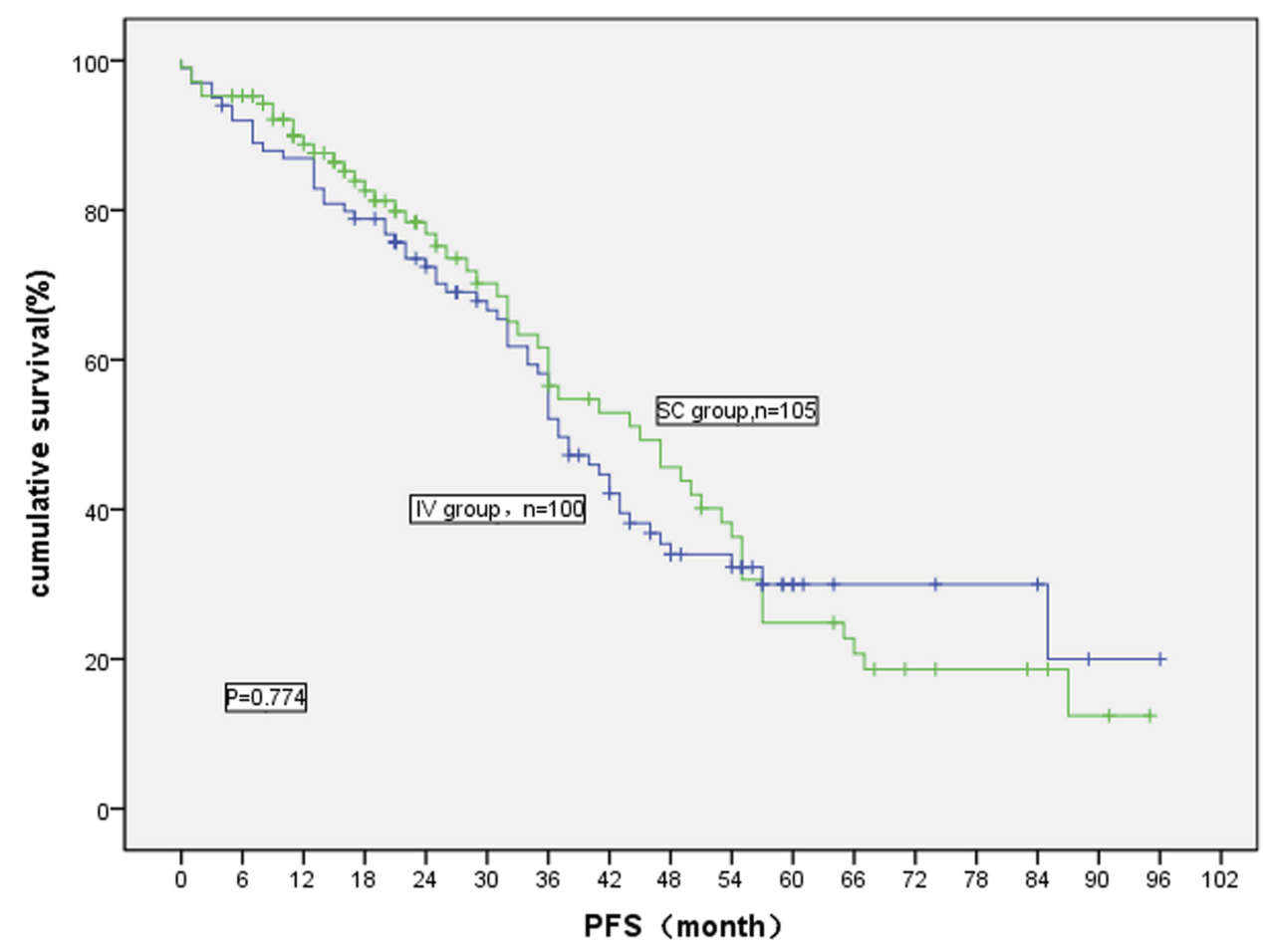

Figure I Comparison of progression-free survival for MM patients treated by bortezomib through different administration methods.

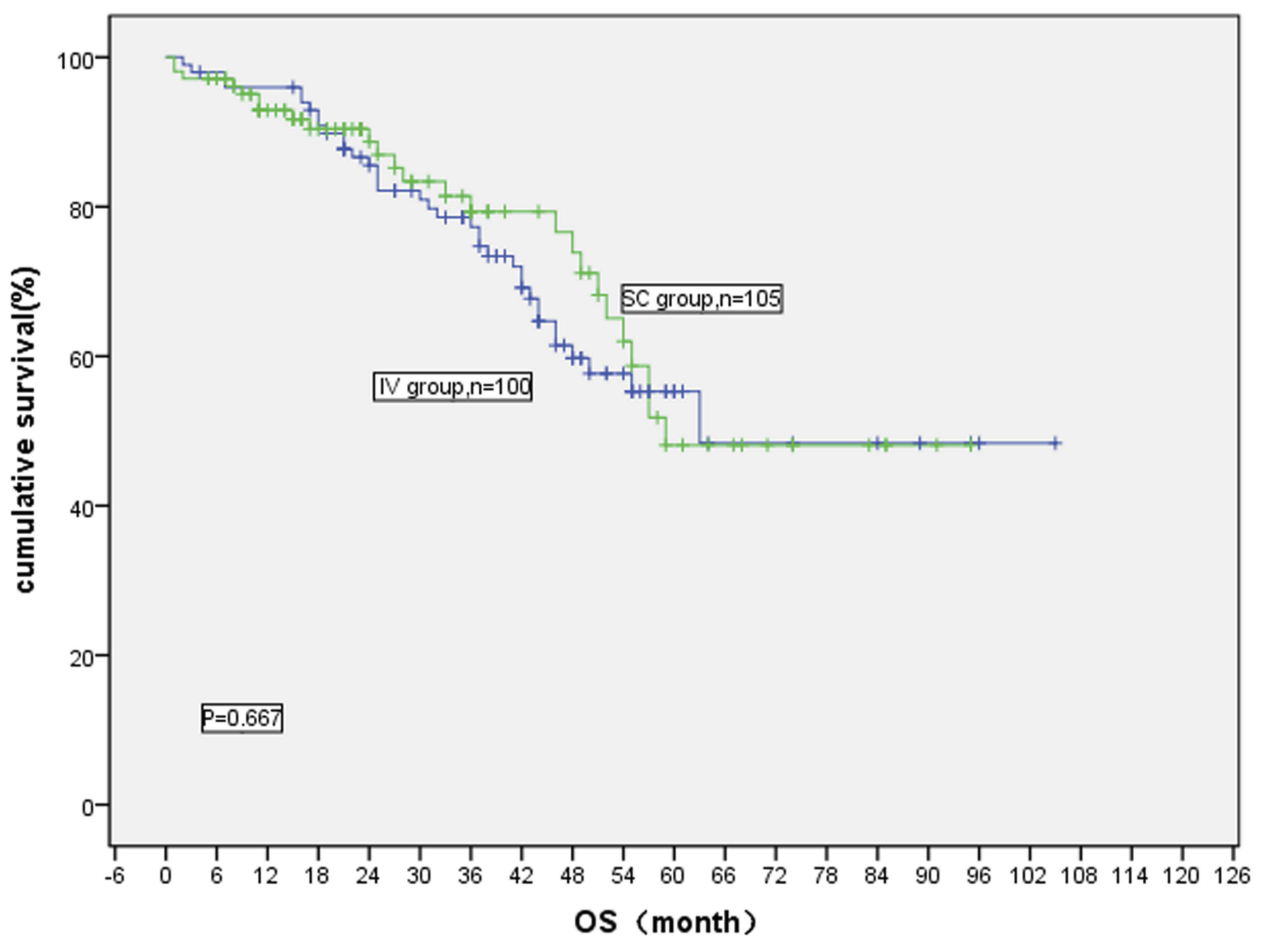

Figure 2 Comparison of overall survival for MM patients treated by bortezomib through different administration methods.

\section{Peripheral neuropathy}

This occurred more after the 3rd course of treatment in the IV injection group, while this occurred more after the 4th course of treatment in the SC injection group. This mainly manifested as numbness of the distal limbs, pain, and abnormal sense of warmth and sense of touch. A total of 
Table 3 Summary of other adverse events

\begin{tabular}{|c|c|c|c|c|}
\hline Adverse events & $\begin{array}{l}\text { IV Group, } \\
\text { N (\%) }\end{array}$ & $\begin{array}{l}\text { SC Group, } \\
\text { N (\%) }\end{array}$ & $\mathrm{CHI}^{2}$ & $P$-value \\
\hline Leukopenia & $47(47.0)$ & $48(45.7)$ & 0.034 & 0.854 \\
\hline$\geq$ Grade 3 & $21(21.0)$ & $16(15.2)$ & 1.150 & 0.284 \\
\hline Thrombocytopenia & $53(53.0)$ & $56(53.3)$ & 0.002 & 0.962 \\
\hline$\geq$ Grade 3 & $20(20.0)$ & $28(26.7)$ & 1.269 & 0.260 \\
\hline Anemia & $48(48.0)$ & 51 (48.6) & 0.007 & 0.935 \\
\hline$\geq$ Grade 3 & $22(22.0)$ & $18(17.1)$ & 0.769 & 0.380 \\
\hline $\begin{array}{l}\text { Peripheral } \\
\text { neuropathy }\end{array}$ & $5 I(51.0)$ & 37 (35.2) & 5.194 & 0.023 \\
\hline Grade I & $20(20.0)$ & $28(26.6)$ & 1.269 & 0.260 \\
\hline Grade 2 & $17(17.0)$ & $7(6.7)$ & 5.291 & 0.021 \\
\hline Grade 3 & II (II.0) & $2(1.9)$ & 7.134 & 0.008 \\
\hline Grade 4 & $3(3.0)$ & $0(0.0)$ & - & - \\
\hline Pulmonary & 71 (7I.0) & $68(64.8)$ & 0.913 & 0.339 \\
\hline infection & & & & \\
\hline$\geq$ Grade 3 & $10(10.0)$ & II (I0.5) & 0.013 & 0.911 \\
\hline $\begin{array}{l}\text { Gastrointestinal } \\
\text { symptoms }\end{array}$ & $59(59.0)$ & $60(57.1)$ & 0.073 & 0.788 \\
\hline Nausea & $2 \mathrm{I}(2 \mathrm{I} .0)$ & $24(22.9)$ & 0.103 & 0.748 \\
\hline Constipation & $12(12.0)$ & $19(18.1)$ & 1.483 & 0.223 \\
\hline Diarrhea & $20(20.0)$ & $18(17.1)$ & 0.277 & 0.599 \\
\hline Abdominal pain & $8(8.0)$ & $5(4.8)$ & 0.904 & 0.342 \\
\hline Bloating & $33(33.0)$ & $32(30.5)$ & 0.151 & 0.698 \\
\hline Paralytic ileus & $7(7.0)$ & $5(4.8)$ & 0.466 & 0.495 \\
\hline Herpes zoster & $30(30.0)$ & $21(20.0)$ & 2.741 & 0.098 \\
\hline Liver damage & $23(23.0)$ & $19(18.1)$ & 0.756 & 0.384 \\
\hline $\begin{array}{l}\text { Urinary tract } \\
\text { infection }\end{array}$ & II (II.0) & $12(11.4)$ & 0.009 & 0.923 \\
\hline
\end{tabular}

Abbreviations: IV, intravenous; SC, subcutaneous; PN, peripheral neuropathy.

51 patients $(51.0 \%)$ in the IV injection group suffered from the PN, including 14 patients with level 3-4 PN. A total of 37 patients in the SC injection group suffered from PN, including two patients with level $3 \mathrm{PN}$, while the remaining patients had level 1-2 PN. The total incidence of PN in the IV injection group was apparently higher when compared with the $\mathrm{SC}$ injection group, and the difference was statistically significant $(P=0.023<0.05)$. It is noteworthy that the incidence was apparently higher in the IV injection group than in the $\mathrm{SC}$ injection group $(P<0.05)$ in the case of $\mathrm{PN} \geq 2$, and the difference was statistically significant.

\section{Pulmonary infection/upper respiratory infection}

This occurs more from the 1 st to 2 nd courses of treatment, and this mainly manifests as fever, cough and sputum, and pharyngeal cavity inflammation, and it shows the change in pulmonary inflammation according to the imageological examination. A total of 71 patients $(71.0 \%)$ in the IV injection group suffered from the pulmonary infection/ upper respiratory infection, including 10 patients with severe pneumonia. A total of 68 patients $(64.8 \%)$ in the SC injection group suffered from pulmonary infection/ upper respiratory infection, including 11 patients with severe pneumonia. After treated by antibacterial, antifungal and antiviral drugs, the infection of the majority of patients was controlled, but this deteriorated to bacteremia for the minority of patients, which could even lead to death.

\section{Digestive tract symptoms}

This mainly manifests as anorexia, nausea and vomiting, constipation, diarrhea, abdominal pain, abdominal distension and paralytic bowel infarction. A total of 59 patients $(59.0 \%)$ in the IV injection group suffered from digestive tract symptoms, including seven patients with paralytic bowel infarction. A total of 60 patients $(57.1 \%)$ in the SC injection group suffered from digestive tract symptoms, including five patients with paralytic bowel infarction. After the occurrence of bowel infarction, the positive expectant treatment relieved the symptoms.

\section{Herpes zoster}

A total of 30 patients $(30.0 \%)$ in the IV injection group suffered from herpes zoster, including one patient who suffered from herpes zoster twice. A total of 21 patients $(20.0 \%)$ in the SC injection group suffered from herpes zoster. These patients got better after the antiviral treatment.

\section{Hepatic injury}

This mainly manifests as an increase of transaminase. A total of 23 patients $(23.0 \%)$ in the IV injection group suffered from hepatic injury. A total of 19 patients (18.1\%) in the SC injection group suffered from hepatic injury. The majority of patients got better after the liver protection treatment.

\section{Urinary system infection}

This mainly manifests as odynuria, urgent urination and growth of bacteria in the urine culture. A total of 11 patients $(11.0 \%)$ in the IV injection group suffered from urinary system infection. A total of 12 patients (11.4\%) in the SC injection group suffered from hepatic injury. These patients got better after the anti-infective treatment. 


\section{Others}

One patient in the IV injection group presented with epilepsy symptoms after six courses of treatment, while one patient in the SC injection group suffered from delirium after two courses of treatment. These patients got better after the expectant treatment, and these patients no longer had the above symptoms after further treatment, according to the original scheme. However, the mental disorder caused by bortezomib could not be reversed.

\section{Discussion}

$\mathrm{MM}$ is a kind of malignant plasmocyte cloning disease. At present, this remains as an incurable hematological system disease and is characterized by marrow plasmocyte clonal expansion, monoclonal immune globulin in the urine, a decrease in immunity and damage of the blood system, bone, kidney and other related target organs. ${ }^{8,9}$ Newly diagnosed patients should immediately receive treatment. The traditional clinical chemotherapy regimen includes MP (melphalan and prednisone), VAD (vincristine, doxorubicin and dexamethasone) and CTD (cyclophosphamide, thalidomide and dexamethasone). These can improve the remission rate and lifetime of $\mathrm{MM}$ patients, but have a high recurrence rate, and can easily lead to drug resistance to chemotherapy. Bortezomib is a kind of boracic acid peptide compound that belongs to the reversible proteasome inhibitor. It can realize the reversible inhibition of the activity of chymotrypsin and trypsin with the $26 \mathrm{~S}$ sigma subunit in the proteasome of the mammalian cell through selective combination with the threonine in the active site of the proteasome. This can subsequently inhibit the genetic expression related to cell proliferation, delay tumor cell growth, induce cell apoptosis and inhibit angiogenesis. $^{10-12}$ Meanwhile, bortezomib can increase the sensitivity of the chemotherapy drug and overcome the resistance of myeloma cells to dexamethasone, doxorubicin, melphalan and other drugs. Various studies have revealed that bortezomib can act on many human tumor cell lines and have a significant effect on hematological malignancy. ${ }^{13}$ Furthermore, bortezomib can produce a significant effect on newly diagnosed and recurrent/refractory patients with myeloma and effectively improve abnormal renal function. ${ }^{14,15}$ However, the PN caused by this would bring great pain to these patients and limit the application of drugs. In order to reduce the incidence of neurotoxicity, the clinical administration method was changed from IV injection to SC injection.
The research data show that the ORR and $\geq$ VGPR in the IV injection group were significantly higher, when compared with those in the SC injection group, after the first course of treatment, and the difference was statistically significant. Studies have shown that the difference in pharmacokinetics and pharmacodynamics between SC injection and IV injection is larger. ${ }^{16-18}$ The blood concentration-time area under the curve of these two groups was basically same within $72 \mathrm{hrs}$, namely, the dose of the drug absorbed into the blood was basically same within 72 hrs. However, compared with SC injection, the SC injection of bortezomib has a higher $\mathrm{C}_{\max }$ (maximum plasma concentration) and shorter $\mathrm{T}_{\max }$ (time to peak), which may partially explain the faster and deeper response observed in the IV injection group. With the continuation of treatment, the remission rate of ORR and VGPR or above in these two groups were basically the same, and the median PFS and OS were also basically the same. This indicates that the IV injection group exhibited a faster response and deeper remission degree, when compared with the SC injection group. With the increase of the course of treatment, the effect was basically the same, which is basically consistent with the results of the retrospective study conducted by $\mathrm{Xu}$ et al. ${ }^{19}$

The present study also reveals that the overall incidence of PN in the SC injection group was significantly lower than that in the IV injection group $(35.2 \%$ vs $51.0 \%, P=0.023)$. In the case of $\mathrm{PN} \geq 2$, the $\mathrm{SC}$ injection group was also significantly lower than the IV injection group (level 2: 6.7\% vs $17.0 \%, P=0.021$; level $31.9 \%$ vs $11.0 \%, P=0.008$; level 4: $0.0 \%$ vs $3.0 \%$ ). The difference in the incidence of other adverse events between these two groups was not statistically significant $(P>0.05)$. In addition, the incidence of PN also increased with the increase in the accumulated dose of bortezomib. The IV injection group and SC injection group reach its peak in the 4 th and 6 th cycles. When the accumulated dose of bortezomib reached $20.8 \mathrm{mg} / \mathrm{m}^{2}$, the incidence of $\mathrm{PN}$ in the $\mathrm{SC}$ injection group is significantly lower than that in the IV injection group $(18.0 \%$ vs $36.6 \%, P=0.027)$. The present study shows that $\mathrm{PN}$ is the adverse reaction correlated to the dose of bortezomib. This may occur in the 1 st cycle, reach the peak in the 5 th cycle with an increase of its accumulated dose, and subsequently enter a plateau period. $^{20-22}$ In summary, the SC injection approach is a safer and more effective administration method.

The present study provides novel findings. These two administration methods have their respective advantages and disadvantages. However, it remains to be determined 
whether a balance can be reached between effect and toxicity while avoiding the disadvantages. For newly diagnosed MM patients and MM patients with renal insufficiency, the IV injection approach can enable a faster and deeper response and rapidly reduce the tumor load. Subsequently, the SC injection approach can provide better tolerance and bring the most benefit for patients. Indeed, more clinical researches are needed to verify these.

In conclusion, we report that, compared with IV administration, SC administration of bortezomib results in significantly reduced toxicity and similar ORR, PFS and OS. This study demonstrated the point that SC bortezomib can provide a better balance between efficacy and toxicity, supported the view that high-risk patients who have previously suffered from nervous system disease, or patients who may develop $\mathrm{PN}$ should prefer the SC injection approach.

\section{Acknowledgment}

The authors would like to thank all patients for their cooperation. This study was supported by National Natural Science Foundation of China (No. 81470287) and Henan Outstanding Person Foundation (No. 2018JR007).

\section{Disclosure}

The authors report no conflicts of interest in this work.

\section{References}

1. Kumar SK, Callander NS, Alsina M, et al. NCCN guidelines insights: multiple myeloma, Version 3. 2018. J Natl Compr Canc Netw. 2018;16:11-20. doi:10.6004/jnccn.2018.0002

2. Kouroukis CT, Baldassarre FG, Haynes AE, et al. Bortezomib in multiple myeloma: a practice guideline. Clin Oncol ( $R$ Coll Radiol). 2014;26:110-119. doi:10.1016/j.clon.2013.11.022

3. Richardson PG, Barlogie B, Berenson J, et al. A phase 2 study of bortezomib in relapsed, refractory myeloma. $N$ Engl $J$ Med. 2003;348:2609-2617. doi:10.1056/NEJMoa030288

4. Tan D, Chng WJ, Chou T, et al. Management of multiple myeloma in Asia: resource-stratified guidelines. Lancet Oncol. 2013;14:e571E581. doi:10.1016/S1470-2045(13)70404-2

5. Mateos MV, San Miguel JF. Safety and efficacy of subcutaneous formulation of bortezomib versus the conventional intravenous formulation in multiple myeloma. Ther Adv Hematol. 2012;3:117-124. doi: $10.1177 / 2040620711432020$

6. Merz M, Salwender H, Haenel M, et al. Subcutaneous versus intravenous bortezomib in two different induction therapies for newly diagnosed multiple myeloma: an interim analysis from the prospective GMMG-MM5 trial. Haematologica. 2015;100:964-969. doi:10.3324/ haematol.2015.124347
7. Anderson KC, Alsina M, Atanackovic D, et al. NCCN guidelines insights: multiple myeloma, Version 3.2016. J Natl Compr Canc Netw. 2016;14:389-400

8. Landgren O, Rajkumar SV. New developments in diagnosis, prognosis, and assessment of response in multiple myeloma. Clin Cancer Res. 2016;22:5428-5433. doi:10.1158/1078-0432.CCR-16-0866

9. Palumbo A, Chanan-Khan A, Weisel K, et al. Daratumumab, bortezomib, and dexamethasone for multiple myeloma. $N$ Engl $J$ Med. 2016;375:754-766. doi:10.1056/NEJMoa1606038

10. Mitsiades N, Mitsiades CS, Poulaki V, et al. Molecular sequelae of proteasome inhibition in human multiple myeloma cells. Proc Natl Acad Sci U S A. 2002;99:14374-14379. doi:10.1073/pnas.202445099

11. Sun CY, Li JY, Chu ZB, Zhang L, Chen L, Hu Y. Efficacy and safety of bortezomib maintenance in patients with newly diagnosed multiple myeloma: a meta-analysis. Biosci Rep. 2017;37:BSR20170304. doi:10.1042/BSR20170304

12. Gandolfi S, Laubach JP, Hideshima T, Chauhan D, Anderson KC, Richardson PG. The proteasome and proteasome inhibitors in multiple myeloma. Cancer Metastasis Rev. 2017;36:561-584. doi:10.1007/ s10555-017-9707-8

13. Chauhan D, Hideshima T, Mitsiades C, Richardson P, Anderson KC. Proteasome inhibitor therapy in multiple myeloma. Mol Cancer Ther. 2005;4:686-692. doi:10.1158/1535-7163.MCT-04-0338

14. Fotiou D, Dimopoulos MA, Kastritis E. Managing renal complications in multiple myeloma. Expert Rev Hematol. 2016;9:839-850. doi:10.1080/17474086.2016.1210003

15. Gavriatopoulou M, Terpos E, Kastritis E, Dimopoulos MA. Current treatments for renal failure due to multiple myeloma. Expert Opin Pharmacother. 2016;17:2165-2177. doi:10.1080/14656566.2016.12 36915

16. Hoy SM. Subcutaneous bortezomib: in multiple myeloma. Drugs. 2013;73:45-54. doi:10.1007/s40265-013-0006-6

17. Moreau P, Pylypenko H, Grosicki S, et al. Subcutaneous versus intravenous administration of bortezomib in patients with relapsed multiple myeloma: a randomised, phase 3, non-inferiority study. Lancet Oncol. 2011;12:431-440. doi:10.1016/S1470-2045(11)700 81-X

18. Moreau P, Karamanesht II, Domnikova N, et al. Pharmacokinetic, pharmacodynamic and covariate analysis of subcutaneous versus intravenous administration of bortezomib in patients with relapsed multiple myeloma. Clin Pharmacokinet. 2012;51:823-829. doi:10.1007/s40262-012-0010-0

19. Xu Y, Deng S, Mao X, et al. Tolerance, kinetics, and depth of response for subcutaneous versus intravenous administration of bortezomib combination in Chinese patients with newly diagnosed multiple myeloma. Clin Lymphoma Myeloma Leuk. 2018;18:422-430. doi:10.1016/j.clml.2018.03.006

20. Windebank AJ, Grisold W. Chemotherapy-induced neuropathy. $J$ Peripher Nerv Syst. 2008;13:27-46. doi:10.1111/j.1529-8027.2008. 00156.x

21. Morawska M, Grzasko N, Kostyra M, Wojciechowicz J, Hus M. Therapy-related peripheral neuropathy in multiple myeloma patients. Hematol Oncol. 2015;33:113-119. doi:10.1002/hon.2149

22. Argyriou AA, Iconomou G, Kalofonos HP. Bortezomib-induced peripheral neuropathy in multiple myeloma: a comprehensive review of the literature. Blood. 2008;112:1593-1599. doi:10.1182/blood-200804-149385 


\section{Publish your work in this journal}

Cancer Management and Research is an international, peer-reviewed open access journal focusing on cancer research and the optimal use of preventative and integrated treatment interventions to achieve improved outcomes, enhanced survival and quality of life for the cancer patient.
The manuscript management system is completely online and includes a very quick and fair peer-review system, which is all easy to use. Visit http://www.dovepress.com/testimonials.php to read real quotes from published authors.

Submit your manuscript here: https://www.dovepress.com/cancer-management-and-research-journal 